\title{
Glycated hemoglobin predicts coronary artery disease in non-diabetic adults
}

\author{
Mohammed Ewid ${ }^{1,2^{*}}$ (D), Hossam Sherif ${ }^{1,3}$, Syed Muhammad Baqui Billah ${ }^{1}$, Nazmus Saquib ${ }^{1}$, Wael AlEnazy ${ }^{1}$, \\ Omer Ragab', Saed Enabi ${ }^{1}$, Tawfik Rajab ${ }^{1}, Z^{2}$ aki Awad ${ }^{4}$ and Rami Abazid ${ }^{4,5}$
}

\begin{abstract}
Background: Coronary artery disease (CAD) is a major cause of morbidity and mortality worldwide. Due to increased CAD risk factors in Saudi Arabia, research on more feasible and predictive biomarkers is needed. We aimed to evaluate glycated hemoglobin ( $\mathrm{HbA} 1 \mathrm{c})$ as a predictor of CAD in low-risk profile non-diabetic patients living in the Al Qassim region of Saudi Arabia.

Methods: Thirty-eight patients with no history of CAD were enrolled in this cross-sectional study. They provided demographic data, and their HbA1c estimation followed the National Glycohemoglobin Standardization Program parameters. All patients underwent coronary computed tomography angiography (CCTA) for evaluation of chest pain. The extent of coronary artery stenosis (CAS) was quantified as percentage for each patient based on plaques detected in CCTA.
\end{abstract}

Results: Mean blood pressure of the patients was $(91.2 \pm 11.9 \mathrm{mmHg}), \mathrm{BMI}\left(28.3 \pm 5.8 \mathrm{~kg} / \mathrm{m}^{2}\right)$, serum cholesterol level $(174 \pm 33.1 \mathrm{mg} / \mathrm{dl}$ ), and HbA1c levels (mean $5.7 \pm 0.45$, median 5.7 and range $4.7-6.4 \%$ ). Eighteen patients showed no CAS (47.4\%), 12 showed minimal stenosis (31.6\%), 3 showed mild stenosis (7.9\%), 3 showed moderate stenosis (7.9\%) and 2 showed severe stenosis (5.3\%). A moderate correlation was detected between $\mathrm{HbA} 1 \mathrm{c}$ and CAS percentages $(r=0.47, p<0.05)$ as well as between HbA1c and the number of affected coronary vessels $(r=0.53, p<0.001)$.

Conclusion: Glycated hemoglobin can be used as a predictive biomarker for CAD in non-diabetic low-risk patients.

Keywords: HbA1c, Coronary artery disease, CAD risk factors

\section{Background}

Coronary artery disease (CAD) is a major health problem in Saudi Arabia, as is the case internationally; an estimated increase of 6.3 million CAD-related deaths is expected worldwide between 2008 and 2030 [1]. This increasing death trend is also true for the middle- and high-income countries belonging to the Gulf Cooperation Council, including Saudi Arabia [2].

The prevalence of major cardiovascular disease (CVD) risk factors, such as diabetes, obesity, hypertension, and physical inactivity, has increased in Saudi Arabia

\footnotetext{
* Correspondence: drmohammedowid@yahoo.com

${ }^{1}$ College of Medicine, Sulaiman Al Rajhi Colleges, P.O. Box 777, Al Bukayriah, Qassim 51941, Saudi Arabia

${ }^{2}$ Internal Medicine Department, Faculty of Medicine, Cairo University, Cairo 11562, Egypt

Full list of author information is available at the end of the article
}

recently. Over the last two decades, obesity has increased from 35.6 to $65.5 \%$, hypertension from 26.1 to $40 \%$, and type 2 diabetes from 10.6 to $32.1 \%$ [3, 4]. It is speculated that rapid economic transition, urbanization, and increased prevalence of CVD risk factors in the population are some of the reasons for the increase of CAD [5].

An effective way to curb the adverse outcomes (i.e., complications, mortality) of a chronic disease like $\mathrm{CAD}$ is to diagnose it early in its development and preferably by non-invasive tools. At present, there are a number of screening tools available for CAD, namely high-sensitivity C-reactive protein, lipoproteinassociated phospholipase A2, ankle-brachial index, and multiple imaging studies like coronary computed tomography angiography (CCTA) with coronary artery calcium scoring [6]. 
Each of the screening tools has its advantages and disadvantages. Unfortunately, there is no settled consensus among clinicians on which tool is more likely to accurately predict fatal and non-fatal CAD-related outcomes [7]. Therefore, there is room for assessment of additional biomarkers that can detect early metabolic changes related to atherosclerosis and CAD.

Glycated hemoglobin (HbA1c), a well-known biomarker that reflects long-term glycemic control, has been an established diagnostic test for diabetic patients since 2010 [8]. Its value for the prediction of microvascular and macrovascular complications among diabetic patients is well established [8]. However, its potential as a screener of CAD among non-diabetic patients has shown mixed results in the literature.

This controversy in the literature regarding HbA1c is still ongoing. There are recent studies that did not find a positive correlation between $\mathrm{HbA1c}$ and cardiovascularrelated outcomes (for example, death, nonfatal myocardial infarction, stroke, or hospitalization due to heart failure) [9]. On the other hand, evidence of positive correlation was detected in other studies, including recent meta-analyses of 22 studies involving 22,428 nondiabetic patients; high $\mathrm{HbA1c}$ levels were associated with a higher rate of long-term death $(\mathrm{OR}=1.76,95 \% \mathrm{CI}=$ 1.44-2.16) and myocardial infarction ( $\mathrm{OR}=1.69,95 \%$ $\mathrm{CI}=1.07-2.67)$. The findings for death remained the same after sensitivity analyses [10].

Moreover, HbA1c cut-off values for atherosclerosis, CAD diagnosis, and stages of coronary artery stenosis (CAS) show diverse results in the literature with evidence for increased CAD risk concomitant with increased HbA1c levels even in non-diabetic populations [11].

There is no available data regarding the above HbA1c cut-off values in the Saudi population. Our research for local HbA1c cut-off values for CAD diagnosis and its stages of severity can be of great help in optimizing the prevention of CAD and its sequelae, especially in high-CAD-risk groups like the Saudi population.

Our main aim is to investigate the role of the biomarker HbA1c as a predictor of CAD in non-diabetic patients with no previous established CAD diagnosis.

\section{Methods}

\section{Study design and participants}

This cross-sectional study included 38 patients who came to the outpatient clinic of Prince Sultan Cardiac Center, Al Qassim for evaluation of their chest pain. They were enrolled in the study between December 2017 and July 2018 after signing the informed consent that explained their rights in the study, the perceived risks and benefits of participation, and the measures taken by the investigators to keep their personal information confidential. The inclusion criterion was non-diabetic adults that had indication for CCTA. A patient was excluded from the study if he/ she had any of the following: (a) previous CAD diagnosis, (b) impaired kidney function detected by urea and creatinine, (c) any end organ failure or malignancy, (d) active infection, (e) diabetes (HbA1c $\geq 6.5 \%$ or fasting glucose $\geq 126 \mathrm{mg} / \mathrm{dL}$ ), (f) previous diabetes diagnosis, or (g) was using anti-diabetic medication and/or statins.

\section{Data collection and laboratory testing}

Upon enrollment, the patients were interviewed with a standard questionnaire for the following data: (a) age (in years), (b) gender (male, female), (c) other demography, and (d) CAD risk factors, including diabetes, hypertension, dyslipidemia, physical inactivity, previous CAD, family history, and drug/substance intake. A basic physical examination was carried out, and an average of three resting blood pressure measurements were taken by a specialized cardiology nurse using a mercury sphygmomanometer. Hypertension was defined as blood pressure $\geq 140 / 90 \mathrm{mmHg}$ or receiving anti-hypertension treatment. Body mass index (BMI) was calculated by dividing weight $(\mathrm{kg})$ by height (meters squared). All patients had blood samples taken before CCTA for laboratory analysis, including urea, creatinine, fasting blood glucose (FBG), lipid profile, and HbA1c. HbA1c (Tina-quant Hemoglobin A1c Gen.3 REF 05336163190 /Roche Diagnostics GmbH-Germany) was estimated according to the National Glycohemoglobin Standardization Program (NGSP) parameters. Criteria of diabetes mellitus diagnosis was defined according to the American Diabetic Association's diagnostic criteria [12]: prediabetic stage [HbA1c 5.7-6.4 / impaired fasting glucose (IFG) (100-125 mg/dL)]; diabetes mellitus (HbA1c $\geq 6.5$ /fasting glucose $\geq 126 \mathrm{mg} / \mathrm{dL}$ ).

\section{CCTA}

All patients had an appointment for evaluation of suspected ischemia via high resolution CCTA with a dualsource 256 slice scanner (Siemens Flash Definition CT scanner; Siemens, Berlin, Germany). After a calcium score scan, we used either a prospective electrocardiography (ECG) triggering or a retrospective ECG gating acquisition. Post-processing and reconstruction of the CCTA were carried out with a Multimodality Workplace (Siemens Medical Solutions, Erlangen, Germany).

\section{CCTA results interpretation}

CCTA images were interpreted by two cardiologists who had at least 6 years of experience in CCTA 
interpretation. Based on the plaques detected in CCTA, CAS was quantified for each patient and was expressed in percentages [13]. Additionally, patients were classified as having minimal $(<25 \%)$, mild (25$49 \%)$, moderate $(50-69 \%)$, and severe $(\geq 70 \%)$ stenosis according to the degree of luminal obstruction [14].

\section{Statistical analysis}

Quantitative variables are presented as mean \pm SD. Qualitative variables are expressed as numbers and proportion. Correlation of HbA1c levels with CAS percentages and the number of affected vessels was determined by means of Spearman's correlation test. A receptive operative characteristics (ROC) curve was generated to assess $\mathrm{HbA} 1 \mathrm{c}$ between patients with and without coronary atherosclerosis. A Box and Whisker's plot was made to assess the HbA1c values with different levels of CAD stenosis. $P$-values less than 0.05 were considered statistically significant. Statistical analyses were performed using SPSS Statistics, version 25 (SPSS Inc., Chicago, Illinois, USA).

\section{Results}

The sample's mean age was 50.8 years (standard deviation, $\mathrm{SD}=9.5$ ), and mean BMI was $28.3 \mathrm{~kg} / \mathrm{m}^{2}$ (SD = 5.8). Sixty-three percent (63\%) were male, $65.5 \%$ were overweight or obese, $29.4 \%$ were hypertensive, and $21.4 \%$ had an above normal cholesterol level $(>200$ $\mathrm{mg} / \mathrm{dl})$.

The HbA1c level was $5.7 \pm 0.45 \%(4.7-6.4 \%)$, and the data indicated that $44.7 \%$ were normal $(<5.6 \%)$ and $55.3 \%$ were pre-diabetic $(5.7-6.4 \%)$ (Table 1$)$.

Eighteen patients showed no CAS (47.4\%), 12 showed minimal stenosis (31.6\%), 3 showed mild stenosis $(7.9 \%)$, 3 showed moderate stenosis (7.9\%), and 2 showed severe stenosis (5.3\%). The mean number of vessels affected was 0.84 (SD 0.95; range 0-3) (Table 2).

Figure 1 shows three examples of CCTA images with their related $\mathrm{HbA1c}$ levels.

HbA1c was not significantly correlated with CVD risk factors like age, systemic hypertension, or the serum

Table 1 Patient characteristics of the sample $(n=38)$

\begin{tabular}{ll}
\hline Variable & Mean \pm SD/ N (\%) \\
\hline Age (years) & $50.87 \pm 9.56$ \\
Male & $24(63.2)$ \\
Overweight/Obese & $19(65.5)$ \\
Hypertensive & $5(29.4)$ \\
High cholesterol & $6(21.4)$ \\
HbA1c (\%) & \\
$\quad$ Normal & $17(44.7)$ \\
Pre-diabetic & $21(55.3)$ \\
\hline
\end{tabular}

Table 2 Distribution of CAS among patients $(n=38)$

\begin{tabular}{llc}
\hline Variable & Mean \pm SD/ N (\%) & Min-Max \\
\hline Stenosis (\%) & $19.6 \pm 19$ & $5-75$ \\
Number of affected vessels & $0.84 \pm 0.95$ & $0-3$ \\
Stenosis severity & \\
$\quad$ Normal & $18(47.37)$ & \\
Minimal & $12(31.58)$ \\
Mild & $3(7.89)$ \\
Moderate & $3(7.89)$ \\
Severe & $2(5.27)$ \\
\hline
\end{tabular}

cholesterol level, and it had only a mild correlation with BMI $(0.4, P<0.05)$.

A moderate correlation could be detected between HbA1c and CAS quantitative percentage $(r=0.470, p<=$ 0.051 ) as well as between $\mathrm{HbA} 1 \mathrm{c}$ and the number of affected coronary vessels $(r=0.5344, \quad p<=0.0011)$ (Table 3).

A receiver operator characteristic (ROC) curve was generated to detect the ability of the HbA1c biomarker to be used as an early predictor for CAS in nondiabetics. The area under the curve was $71 \%$ (95\% CI; 64-96\%), with the best cut-off value of HbA1c at $5.9 \%$ (sensitivity $67 \%$ \& specificity $74 \%$ ) (Fig. 2).

\section{Discussion}

A salient finding of this study was a moderate correlation between $\mathrm{HbA} 1 \mathrm{c}$ and CAS percentages among non-diabetic patients. This finding is in agreement with a recent study by Ikeda et al. [15] that showed a higher HbA1c level as an independent risk factor of CAS. Previous studies, some of which included meta-analysis, found a positive correlation between HbA1c and cardiovascular events in non-diabetic adults [16-18]; however, these studies did not test the correlation between $\mathrm{HbA1c}$ and severity of CAS based on CCTA findings.

Geng et al. [10] conducted a meta-analysis using 20 studies involving 22,428 patients to investigate HbA1c correlation with clinical CAD outcomes; they found that an elevated HbA1c level increased the risks of both long-term mortality (odds ratio 1.76, 95\% confidence interval 1.44-2.16, $p<.001)$ and myocardial infarction (MI, odds ratio $1.69,95 \%$ confidence interval $1.07-2.67, p=.026)$, but not the risk of early death in non-diabetic patients with CAD. More recently, Haring et al. [19] showed a positive association between high-normal HbA1c levels and increased CVD risk and mortality. On the other hand, there are studies that do not support that notion, such as by Liu et al. [20] and Shin et al. [21], in which HbA1c was 

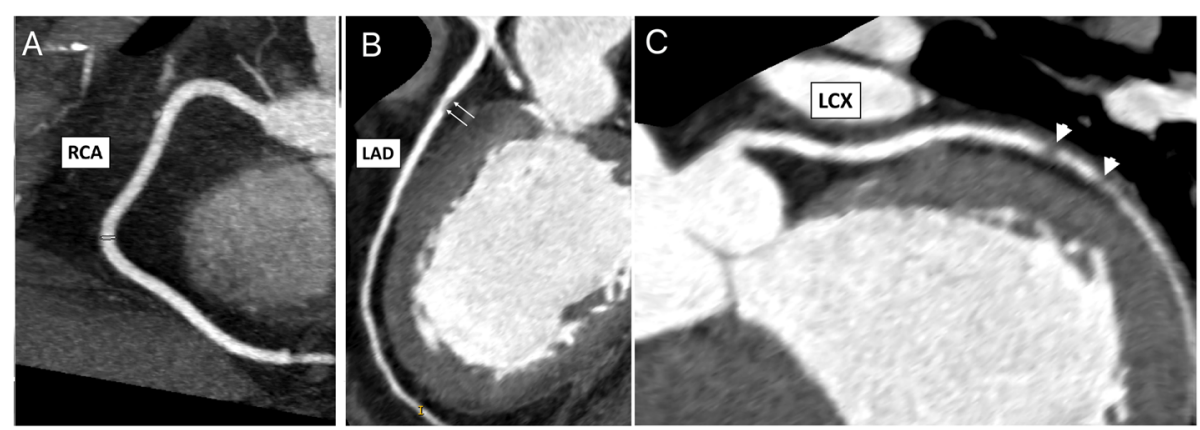

Fig. 1 Mutiplaner reconstruction CCTA images for 3 studied cases with rising $\mathrm{HbA} 1 \mathrm{c}$ levels. a. Normal right coronary artery $(\mathrm{RCA}), \mathrm{HbA1C}=4.8 \%$; b Mild stenosis at proximal left descending coronary artery $L A D$ stenosis, $\mathrm{HbA1C}=5.8 \%$; and (c) Severe stenosis of the left circumflex coronary artery $(L C X), H b A 1 C=6.3 \%$

not associated with prognosis among non-diabetic patients with myocardial infarction.

A number of factors may explain the discrepancy in results between these studies. Some studies recruited young people with favorable cardiac risk profiles, while other studies had more elderly participants with already advanced CAD complications [20]. A few studies resorted to retrospective design, and therefore, may have missed unrecorded adverse cardiac events [22]. The studies also varied in the outcomes that they were interested in, which ranged from very early changes in the arterial wall pathology [15], to short-term clinical adverse outcomes [23],to long-term morbidity and mortality [10].

This study's finding of an HbA1c cut-off value of $5.9 \%$ to differentiate coronary stenosis among nondiabetic patients is supported by findings from other studies although there is no Saudi data available for comparison. Ashraf et al. [24] studied 299 nondiabetic patients who had coronary angiography for suspected ischemia and reported that anHbA1c level of $5.6 \%$ could be used for CAD-specific risk stratification (OR: 2.8, 95\% CI: 1.3-6.2, p-value: 0.009). Tomizawa et al. [25] found that an HbA1c level above 6\% was associated with significant CVD risk in nondiabetic patients.

Our study focused on pre-diabetic patients, who are usually overlooked and neglected in clinical practice although endothelial dysfunction, the main pathogenesis of both micro and macrovascular diabetic complications, starts to develop in this early stage [26]. Consequently, this study highlights the significance of sub-threshold

Table 3 Correlation of $\mathrm{HbA} 1 \mathrm{c}$ with CAS percentage \& number of affected vessels

\begin{tabular}{lll}
\hline & Percentage of stenosis & Number of vessels \\
\hline Spearman'sr-value & 0.47 & 0.53 \\
$p$-value & $<0.05$ & $<0.001$ \\
$\mathrm{~N}$ & 38 & 38 \\
\hline
\end{tabular}

levels of $\mathrm{HbA} 1 \mathrm{c}$ in a pre-diabetic condition as an early predictor of CAS.

A recently published study by Engel et al. [26] compared the endothelial permeability, which is considered a hallmark of CAD, with different HbA1c levels using an albumin-binding MR probe. This crosssectional study included 26 patients and concluded that patients with both intermediate and high HbA1clevels are associated with a larger extent of endothelial damage of the coronary arteries as compared to patients with HbA1c levels below 5.7\% [27].

Abnormal glucose regulation (AGR) and insulin resistance are thought to be crucial factors for the development of subclinical atherosclerosis and, consequently, CAD. In fact, AGR has been independently associated with acute coronary events [23]. Additionally, insulin resistance and CAD have been found to co-exist in newly diagnosed patients with impaired glucose tolerance and impaired fasting glucose [28].

The increase in serum $\mathrm{HbA1c}$ is likely to be associated with the increase in the number of coronary vessels affected with stenosis. As the study by Haring et al. [19] found a positive link between high-normal HbA1c levels and increased risk of subclinical atherosclerosis (0.02 $\mathrm{mm}$ increase in the thickness of common carotid artery media per $1 \%$ increase in $\mathrm{HbA1c}$ ), so did we find a positive correlation between serum HbA1c and the affected number of coronary vessels with stenosis. Our results further corroborated the findings of the study by Tomizawa et al. [25],who investigated the relationship of HbA1c and coronary plaque characteristics and reported that plaque formation in the coronary vessels was twice as likely (OR 2.19, 95\% CI $=1.37-3.45, p=0.005$ ) in patients with elevated $\mathrm{HbA1c}$ levels.

This study was the first in Saudi Arabia to assess the relationship between serum HbA1c and CAS by CCTA. Moreover, its participants were non-diabetic with relatively low CAD risk, so the study showed the role HbA1c could play in the prevention and monitoring of 


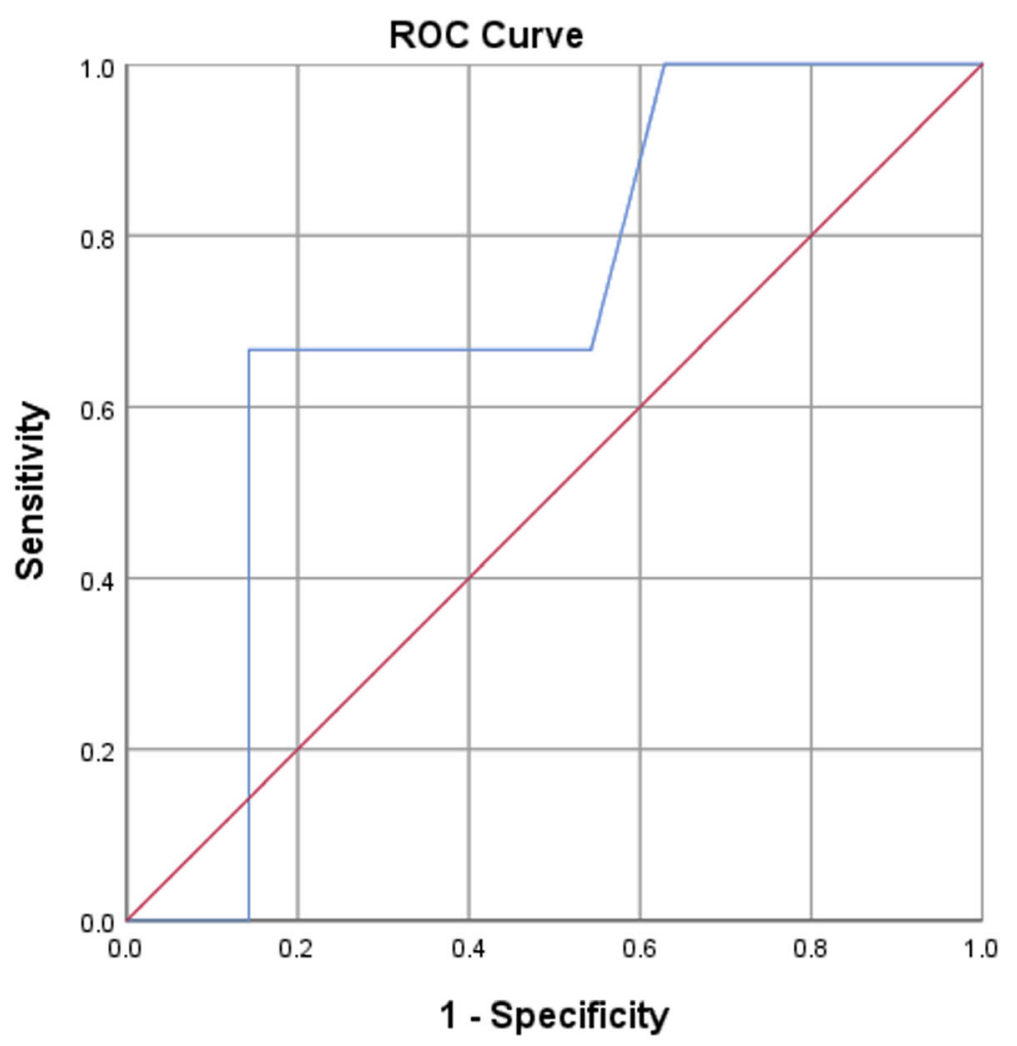

Diagonal segments are produced by ties.

Fig. 2 ROC curve for prediction of CAS using glycated hemoglobin level

CAD among those who are otherwise free from cardiac events. Finally, HbA1c, which was the focus of this study, is a standardized and widely available test that can be easily employed in primary healthcare centers for early prevention of CAD events.

\section{Limitations}

This study has few limitations. It was a single-center study and therefore may not have enrolled a full spectrum of pre-diabetic patients. It also had a small sample size. Future studies should employ larger samples and enroll patients from multiple sites to validate the findings of this study. Finally, the cross-sectional nature of this study with no follow up of the patients precluded it from establishing a temporal relationship between HbA1c and CAD. Future studies should employ a cohort design to follow up the patients. Additionally, trials could be undertaken to test the effect of lowering HbA1c on CAS in pre-diabetic patients.

\section{Conclusions}

Based on our findings, we conclude that glycated hemoglobin A1c can be used as a predictive biomarker for $\mathrm{CAD}$ in non-diabetic patients with a cut-off value of $5.9 \%$.

\section{Abbreviations}

AGR: Abnormal glucose regulation; BMI: Body mass index; CAD: Coronary artery disease; CAS: Coronary artery stenosis; CCTA: Coronary computed tomography angiography; CVD: Cardiovascular disease; ECG: Electrocardiography; FBG: Fasting blood glucose; HbA1c: Glycated hemoglobin; IFG: Impaired fasting glucose; LAD: Left anterior descending coronary artery; LCX: Left circumflex coronary artery; MPR: Mutiplaner reconstruction; NFG: Normal fasting glucose; NGSP: National

Glycohemoglobin Standardization Program; RCA: Right coronary artery; ROC: Receiver operator characteristic curve

\section{Acknowledgements}

The authors thank Ms. Erin Strotheide for her editorial contributions to this manuscript.

\section{Authors' contributions}

ME conceived of the idea, developed the theory, supervised the findings, and wrote the manuscript. HS shared in the methodology structure and analytical plan, and provided critical feedback. SB developed the theoretical formalism, performed the computations and the numerical simulations. NS designed the model and the computational framework, verified the analytical methods, developed the theoretical formalism, performed the analytic calculations, and helped supervise the project. WA, OR, SE \& TR collected patient data. ZA shared in the practical work of coronary $C T$ angiography. RA was the principle investigator, conceived of the idea, shared in the practical work of coronary CT angiography, supervised the findings, and wrote the manuscript. All authors read and approved the final manuscript. 


\section{Funding}

The authors received no specific funding for this work.

\section{Availability of data and materials}

The datasets used and/or analyzed during the current study are available from the corresponding author on reasonable request.

\section{Ethics approval and consent to participate}

Ethical approval from the regional research ethics committee was taken prior to commencing the study (Al Qassim providence, KSA Ministry of Health, approval number 45/44/1508). All patients signed informed consents matching with the committee regulations prior to their participation in the study.

\section{Consent for publication}

Not applicable.

\section{Competing interests}

The authors declare that they have no competing interests.

\begin{abstract}
Author details
'College of Medicine, Sulaiman Al Rajhi Colleges, P.O. Box 777, Al Bukayriah, Qassim 51941, Saudi Arabia. ${ }^{2}$ Internal Medicine Department, Faculty of Medicine, Cairo University, Cairo 11562, Egypt. ${ }^{3}$ Critical Care Medicine Department, Faculty of Medicine, Cairo University, Critical Care, Kasr A. Ainy St, Cairo 11562, Egypt. ${ }^{4}$ Prince Sultan Cardiac Center, Ministry of Health, Al Qassim, Qassim 52366, Buraydah 7430 An Naziyah, Saudi Arabia. ${ }^{5}$ Department of Nuclear Medicine, London Health Sciences Center, 800 Commissioners Road East, PO Box 5010, London, ON N6A 5W9, Canada.
\end{abstract}

Received: 14 February 2019 Accepted: 8 December 2019 Published online: 21 December 2019

\section{References}

1. Lagerweij GR, de Wit GA, Moons KGM, Verschuren WMM, Boer JMA, Koffijberg H. Predicted burden could replace predicted risk in preventive strategies for cardiovascular disease. J Clin Epidemiol. 2018;93:103-11. https://doi.org/10.1016/j.jclinepi.2017.09.014

2. Abdul Rahim HF, Sibai A, Khader Y, Hwalla N, Fadhil I, Alsiyabi H, et al. Non-communicable diseases in the Arab world. Lancet. 2014;383(9914): 356-67. https://doi.org/10.1016/S0140-6736(13)62383-1.

3. Ahmed AM, Hersi A, Mashhoud W, Arafah MR, Abreu PC, Al Rowaily MA, et al. Cardiovascular risk factors burden in Saudi Arabia: the Africa Middle East cardiovascular epidemiological (ACE) study. J Saudi Heart Assoc. 2017; 29(4):235-43. https://doi.org/10.1016/j.jsha.2017.03.004.

4. Alharbi NS, Almutari R, Jones S, Al-Daghri N, Khunti K, De Lusignan S. Trends in the prevalence of type 2 diabetes mellitus and obesity in the Arabian Gulf States: systematic review and meta-analysis. Diabetes Res Clin Pract. 2014;106(2):e30-3. https://doi.org/10.1016/j.diabres.2014.08.019.

5. Yusuf S, Reddy S, Ounpuu S, Anand S. Global burden of cardiovascular diseases: part I: general considerations, the epidemiologic transition, risk factors, and impact of urbanization. Circulation. 2001 Nov; 104(22): 2746-53.

6. Degrell P, Sorbets E, Feldman LJ, Steg PG, Ducrocq G. Screening for coronary artery disease in asymptomatic individuals: why and how? Arch Cardiovasc Dis. 2015;108(12):675-82. https:/doi.org/10.1016/j.acvd.2015.10.001.

7. Ambrose JA, Najafi A. Strategies for the prevention of coronary artery disease complications: can we do better? Am J med. 2018:1-7. https://doi. org/10.1016/j.amjmed.2018.04.0068. American Diabetes Association. Diagnosis and classification of diabetes mellitus. Diabetes Care 2010;33 (Suppl 1):S62-9, https://doi.org/10.2337/dc10-S062.

8. Jovanovic L, Savas H, Mehta M, Trujillo A, Pettitt DJ. Frequent monitoring of A1C during pregnancy as a treatment tool to guide therapy. Diabetes Care. 2011;34(1):53-4. https://doi.org/10.2337/dc10-1455.

9. Shahim B, De Bacquer D, De Backer G, Gyberg V, Kotseva K, Mellbin L, et al. The prognostic value of fasting plasma glucose, two-hour postload glucose, and $\mathrm{HbA} 1 \mathrm{c}$ in patients with coronary artery disease: a report from EUROASPIRE IV: a survey from the european society of cardiology. Diabetes Care. 2017;40(9):1233-40. https://doi.org/10.2337/ dc17-0245.

10. Geng J, Zhang Y, Wang B, Xie J, Xu B, Li J. Glycosylated hemoglobin levels and clinical outcomes in nondiabetic patients with coronary artery disease: a meta-analysis. Medicine (Baltimore). 2017;96(17):1-6. https://doi.org/10. 1097/MD.0000000000006784.

11. Sarwar N, Aspelund T, Eiriksdottir G, Gobin R, Seshasai SR, Forouhi NG, et al. Markers of dysglycaemia and risk of coronary heart disease in people without diabetes: Reykjavik prospective study and systematic review. PLoS Med. 2010;7(5):1-11. https://doi.org/10.1371/journal.pmed.1000278.

12. American Diabetes Association. 2. Classification and diagnosis of diabetes: standards of medical care in diabetes-2018. Diabetes Care. 2018;41(Suppl 1):S13-27. https://doi.org/10.2337/dc18-S002.

13. Sun Z, Ng CKC, Xu L, Fan Z, Lei J. Coronary CT angiography in heavily calcified coronary arteries: improvement of coronary lumen visualization and coronary stenosis assessment with image postprocessing methods. Medicine (Baltimore). 2015;94:1-10. https://doi.org/10.1097/MD. 0000000000002148.

14. Raff GL, Chinnaiyan KM, Cury RC, Garcia MT, Hecht HS, Hollander JE, et al. SCCT guidelines on the use of coronary computed tomographic angiography for patients presenting with acute chest pain to the emergency department: a report of the society of cardiovascular computed tomography guidelines committee. J Cardiovasc Comput Tomogr. 2014;8(4): 254-71. https://doi.org/10.1016/j.jcct.2014.06.002.

15. Ikeda N, lijima R, Hara H, Moroi M, Nakamura M, Sugi K. Glycated hemoglobin is associated with the complexity of coronary artery disease, even in non-diabetic adults. J Atheroscler Thromb. 2012;19(12):1066-72. https://doi.org/10.5551/jat.13722.

16. Selvin E, Steffes MW, Zhu H, Matsushita K, Wagenknecht L, Pankow J, et al. Glycated hemoglobin, diabetes, and cardiovascular risk in nondiabetic adults. N Engl J Med. 2010;362(9):800-11. https://doi.org/10.1056/ NEJMoa0908359.

17. Khaw K-T, Wareham N, Bingham S, Luben R, Welch A, Day N. Association of hemoglobin a 1c with cardiovascular disease and mortality in adults: the European prospective investigation into cancer in Norfolk. Ann Intern Med. 2004;141(6):413. https://doi.org/10.7326/ 0003-4819-141-6-200409210-00006.

18. Liu Y, Yang YM, Zhu J, Tan HQ, Liang Y, Li JD. Prognostic significance of hemoglobin A1c level in patients hospitalized with coronary artery disease. A systematic review and meta-analysis. Cardiovasc Diabetol. 2011;10(1):98. https://doi.org/10.1186/1475-2840-10-98.

19. Haring $R$, Baumeister SE, Lieb W, von Sarnowski B, Völzke H, Felix SB, et al. Glycated hemoglobin as a marker of subclinical atherosclerosis and cardiac remodeling among non-diabetic adults from the general population. Diabetes Res Clin Pract. 2014;105(3):416-23. https://doi.org/ 10.1016/j.diabres.2014.05.004.

20. Liu Y, Yang YM, Zhu J, Tan HQ, Liang Y, Li JD. Haemoglobin A1C, acute hyperglycaemia and short-term prognosis in patients without diabetes following acute ST-segment elevation myocardial infarction. Diabet Med. 2012;29(12):1493-500. https://doi.org/10.1111/j.1464-5491.2012.03641.x.

21. Shin D, Ahn J, Cha KS, Park JS, Oh JH, Lee HW, et al. Impact of initial glycosylated hemoglobin level on cardiovascular outcomes in prediabetic patients with ST-segment elevation myocardial infarction undergoing primary percutaneous coronary intervention. Coron Artery Dis. 2016;27(1): 40-6. https://doi.org/10.1097/MCA.0000000000000305.

22. Wan EYF, Fung CSC, Yu EYT, Chin WY, Fong DYT, et al. Effect of multifactorial treatment targets and relative importance of hemoglobin A1C blood pressure, and low-density lipoprotein-cholesterol on cardiovascular diseases in Chinese primary care patients with type 2 diabetes mellitus: a population-based ret. J Am Heart Assoc. 2017;6(8):1-13. https://doi.org/10. 1161/JAHA.117.006400.

23. Meng L, Wang HY, Ding WH, Shi LB, Liu L, Jiang J, et al. Abnormal glucose regulation in Chinese patients with coronary artery disease: a cross-sectional study. Medicine (Baltimore). 2017 Dec;96(52):e9514. https://doi.org/10.1097/ MD.0000000000009514.

24. Ashraf H, Boroumand MA, Amirzadegan A, Talesh SA, Davoodi G. Hemoglobin A1C in non-diabetic patients: an independent predictor of coronary artery disease and its severity. Diabetes Res Clin Pract. 2013. https://doi.org/10.1016/j.diabres.2013.10.011.

25. Tomizawa N, Inoh S, Nojo T, Nakamura S. The association of hemoglobin $\mathrm{A} 1 \mathrm{C}$ and high risk plaque and plaque extent assessed by coronary computed tomography angiography. Int J Card Imaging. 2016;32(3):493500. https://doi.org/10.1007/s10554-015-0788-6.

26. Owei I, Umekwe N, Mohamed H, Ebenibo S, Wan J, Dagogo-Jack S. Ethnic disparities in endothelial function and its cardiometabolic correlates: the 
pathobiology of prediabetes in a biracial cohort study. Front Endocrinol (Lausanne). 2018;9:1-8. https://doi.org/10.3389/fendo.2018.00094.

27. Engel LC, Landmesser U, Goehler A, Gigengack K, Wurster T, Manes C, et al. Noninvasive imaging of endothelial damage in patients with different HbA1c-levels, a proof-of-concept study. Diabetes. 2018. https://doi.org/10. 2337/db18-0239.

28. Wang H, Hu B, Lu W, Liu F, Feng B. The relationship of angiographically defined coronary artery disease with insulin sensitivity and secretion in subjects with different glucose tolerance. J Cardiol. 2012;60(5):367-71. https://doi.org/10.1016/j.jjcc.2012.06.008.

\section{Publisher's Note}

Springer Nature remains neutral with regard to jurisdictional claims in published maps and institutional affiliations.

- fast, convenient online submission

- thorough peer review by experienced researchers in your field

- rapid publication on acceptance

- support for research data, including large and complex data types

- gold Open Access which fosters wider collaboration and increased citations

- maximum visibility for your research: over $100 \mathrm{M}$ website views per year

At $\mathrm{BMC}$, research is always in progress.

Learn more biomedcentral.com/submissions 